\title{
Risk evaluation for the navigation environment of the LNG ship based on the cloud model
}

\author{
Shiyuan Zhang ${ }^{1}$, Lianbo $\mathrm{Li}^{2}$ and Xinze $\mathrm{Li}^{3}$ \\ ${ }^{1}$ Navigation College, Dalian Maritime University, 212, 3800 laboratory, 1 Linghai Road, Ganjingzi District, Dalian 116029, Liaoning, China, \\ $86-15941196261$ \\ ${ }^{2}$ Navigation College, Dalian Maritime University, 405, Administration Building, 1 Linghai Road, Ganjingzi District, Dalian 116029, Liaoning, \\ China, 86-18900982638 \\ ${ }^{3}$ Navigation College, Dalian Maritime University, 212, 3800 laboratory, 1 Linghai Road, Ganjingzi District, Dalian 116029, Liaoning, China, \\ $86-13709875988$
}

\begin{abstract}
In order to enhance water transport safety of the LNG ship and improve the objectivity of risk assessment of LNG ships navigation environment, the cloud model which can realize the conversion between qualitative and quantitative evaluation indexes is used to evaluate the LNG ships navigation environment. Combined with the Delphi method, cloud weight and cloud model of indexes at all levels in the evaluation system are determined. At the same time, simulation is carried out by MATLAB software and cloud chart is obtained. And then we analyze the risk level of different factors in LNG ships navigation environment to get the evaluation results, which provides decision-making basis for navigation safety management. Overall, it is testified that the cloud model can reduce the randomness and fuzziness in the process of evaluating and the irrationality caused by the subjective assumption of weight distribution, which makes the results more reasonable and credible.
\end{abstract}

\section{Introduction}

In recent years, natural gas has already become the major energy consumption, while the storage of natural gas is inadequate in China. Importing natural gas through waterway transportation is the main method for people in China to acquire. Therefore, LNG transportation has become an indispensable part of shipping. In view of the flammability of LNG, an increasing number of people concentrate on navigation safety of LNG ship [1-2].

Nowadays, there are many kinds of methods which are used to evaluate the risks of navigation safety. In order to ensure the maritime navigation safety of Xiamen port and improve the efficiency of port operations, Huang Pengfei uses AHP-Fuzzy comprehensive evaluation to evaluate the navigation safety of Xiamen port. They propose corresponding countermeasures and suggestions of various risks control [3]. Zhu Jingjun uses a comprehensive evaluation method to evaluate several ports. Case studies indicate that the model uses fewer indexes and facilitates the weighing of factors [4]. Zheng Yibin uses quantitative analysis on the evaluation index to get the overall actual evaluation on the channel maintenance level of the region [5]. Fan Yaotian uses the modified model which combines BP neural network with cluster analysis to reduce effects of experts' subjectivity when evaluating the severity of marine traffic flow conflicts [6]. Li Lianbo uses two kinds of calculation methods of grey connection degree to comparatively analyze marine accidents between 2009 and 2013 in Liaoning waters and predict the traffic situation in the future [7]. There is a certain reference for the outcome of navigation evaluation by using the above methods, but they ignore the fuzziness of navigation safety to some degree. What's more, during the evaluating process, the feedback from different experts according the same factor is random and the measuring data which are limited by the lack of equipment are also uncertainty. Therefore, we should not only consider the fuzziness of navigation safety, but also consider the randomness and uncertainty of various factors during evaluating the navigation safety.

On the basis of fuzzy mathematics and probability statistics, the cloud model [8-9] combines the fuzziness, randomness and uncertainty of the qualitative concepts in the natural language together, so as to realize the natural transformation between the qualitative and the quantitative. Considering the fuzziness of navigation safety, this paper combines the advantages of the cloud model and calculates the weight of the evaluation index of navigation safety at all levels to reduce the influence of subjective factors on the weight of the evaluation indexes at all levels. In addition, the establishment of the cloud model can fulfill the transformation between the qualitative and quantitative evaluation indexes, which can reasonably solve the problem of randomness and uncertainty in the traditional methods, and make the evaluation result more reasonable. 


\section{Construction of risk assessment index for navigation environment of jiangsu binhai Ing vessel}

LNG industry has always believed that natural gas leakage is the biggest potential risk of the receiving station. SIGTTO (The Society of International Gas Tanker and Terminal Operators) believes that one of the main links of the LNG leakage risk caused by the LNG receiving station is the navigation process of the $\mathrm{LNG}$ ship in the channel.

Therefore, this paper, based on the specific conditions of the Jiangsu seashore and the characteristics of the navigation environment in the waters of Jiangsu, evaluates the environmental risks of the navigation of Jiangsu coastal LNG ships from human factors, ship factors, environmental factors (including hydrology, meteorology and traffic environment) and management factors, and establishes an evaluation index system, see Table1.

Table 1. Transportation environmental risk assessment index system for LNG ship of Jiangsu Province

\begin{tabular}{|c|c|c|}
\hline $\begin{array}{c}\text { Primary } \\
\text { index }\end{array}$ & $\begin{array}{c}\text { Secondary } \\
\text { index }\end{array}$ & Third-level index \\
\hline \multirow{15}{*}{ 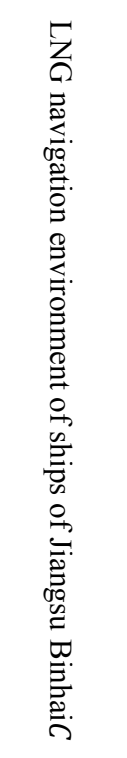 } & \multirow{3}{*}{$\begin{array}{l}\text { Human } \\
\text { factor } C_{1}\end{array}$} & Competence $C_{11}$ \\
\hline & & Education $C_{12}$ \\
\hline & & Safety consciousness $C_{13}$ \\
\hline & \multirow{3}{*}{ Ship factor $C_{2}$} & Ship scale $C_{21}$ \\
\hline & & Maneuverability $C_{22}$ \\
\hline & & Ship equipment $C_{23}$ \\
\hline & \multirow{5}{*}{$\begin{array}{l}\text { Environmental } \\
\text { factor } C_{3}\end{array}$} & Wind and wave $C_{31}$ \\
\hline & & Visibility $C_{32}$ \\
\hline & & Channel length and width $C_{33}$ \\
\hline & & Navigation obstruction $C_{34}$ \\
\hline & & Traffic flow $C_{35}$ \\
\hline & \multirow{4}{*}{$\begin{array}{l}\text { Management } \\
\text { factor } C_{4}\end{array}$} & Tug $C_{41}$ \\
\hline & & Traffic service $C_{42}$ \\
\hline & & Maritime supervision $C_{43}$ \\
\hline & & Emergency resources $C_{44}$ \\
\hline
\end{tabular}

Without effective control of factors affecting navigation safety, navigation accidents may occur. Risk assessment is on the basis of determining the risk and knowing its distribution, analyzing various factors affecting the degree of risk, finding key risk factors through the method of primary and secondary arrangement, providing the decision basis for the managers and ensuring the navigation safety of the waters.

\section{The theory of cloud model}

\subsection{The definition of cloud and its digital features}

Let $\mathrm{C}$ be a qualitative concept on the quantitative domain $\mathrm{U}$ represented by exact data. If quantitative value $x \in U, x$ is a random implementation on $\mathrm{C}$ and the membership degree $\mu(x) \in[0,1]$ of $\mathrm{C}$ to $x$ is a stable random number of $\mu: U \rightarrow[0,1], x \in U, x \rightarrow \mu(x)$, the distribution of $x$ on the domain $\mathrm{U}$ is called cloud, and each $X$ is called a cloud droplet $(x, \mu(x))$.

The three numerical characteristics of cloud are mean $E x$, entropy $E n$ and super entropy $H e$ respectively, which can be recorded as $A=T(E x, E n, H e)$. They distribute mainly between $[E x-3 E n, E x+3 E n]$.The qualitative concept is reflected by quantitative concept, and the mean $E x$ is the most representative one. EntropyEnis used to counter the fuzziness of the model, reflecting the range of the samples contained in the concept. The super entropyHerepresents the uncertainty of entropy $E n$, which reflects the randomness of qualitative concepts and the degree of dispersion of models. Figure 1 is a cloud picture of $(E x=20, E n=$ $3, \mathrm{He}=0.2$ ) respectively.

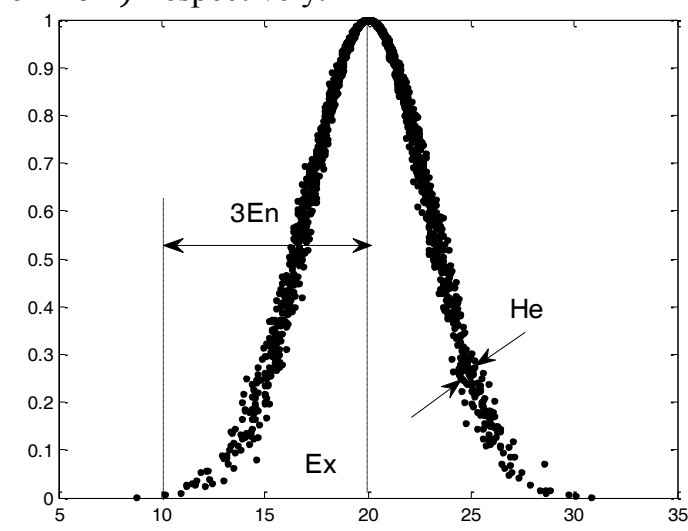

Figure1. The digital features of the cloud.

The $\mathrm{X}$ axis represents a value corresponding to $\mathrm{C}$, and the $\mathrm{Y}$ axis represents the corresponding membership degree.

\subsection{Cloud generator}

The basic operations of the cloud model include the normal cloud generator and the reverse cloud generator [10].

(1)The principle of the normal cloud generator is that after the input of three digital features $E x 、 E n$ 、Heof the cloud, an example of random occurrence under this concept can be obtained, as follows.

Input: The three eigenvalues of the qualitative conceptEx、En、Heand the number of cloud droplets required $N$

Process: Generating a normal random number $E^{\prime} n$, which satisfies $E n^{\prime} \sim N\left(E n, H e^{2}\right)$; Generating a normal random number $x i \sim N\left(E x, E^{\prime} n^{2}\right)$; Carrying on a calculation toyiwith $y i=\exp \left[-(x i-E x)^{2} / 2\left(E^{\prime} n\right)^{2}\right]$; Producing cloud droplets $(x i, y i)$ and repeating the above steps until the expected number of cloud droplets is obtained.

Output: A number of cloud droplets and their determination are obtained. 
(2)The principle of the inverse cloud generator is to transform the actual data into qualitative concepts of $(E x, E n, H e)$ and the specific algorithm is as follows.

Input: A number of cloud droplets and their determination.

Process: Calculating mean of sample with $\bar{X}=$ $\frac{1}{n} \sum_{i=1}^{n} x i$, absolute center distance of first order sample with $\frac{1}{N} \sum_{i=1}^{n}|x i-\bar{X}|$ and sample variance with $S^{2}=$ $\frac{1}{n-1} \sum_{i=1}^{n}(x i-\bar{X})^{2}$;

The expectation of sample:

$$
E x=\frac{1}{n} \sum_{i=1}^{n} x i
$$

The entropy of sample:

$$
E n=\sqrt{\frac{\pi}{2}} \times \frac{1}{N} \sum_{i=1}^{n}|x i-\bar{X}|
$$

The super entropy of the sample:

$$
H e=\sqrt{S^{2}-E n^{2}}
$$

Output: Qualitative concept of samples and expected $E x$, entropyEn and super entropyHe.

\subsection{Basic operation of cloud model}

The cloud computing whose essence is the operation of cloud computing to form a virtual cloud is necessary for risk assessment of LNG vessel navigation environment [11]. If there are two cloud models $C 1(E x 1, E n 1, H e 1)$ and $C 2(E x 2, E n 2, H e 2)$ on the same domain, the resulting virtual cloud is $C(E x, E n, H e)$. The calculation formula is followed, see

\begin{tabular}{|c|c|c|c|}
\hline Operation rule & $E x$ & $E n$ & He \\
\hline+ & $E x_{1}+E x_{2}$ & $\sqrt{E n_{1}^{2}+E n_{2}^{2}}$ & $\sqrt{E n_{1}^{2}+E n_{2}^{2}}$ \\
\hline- & $E x_{1}-E x_{2}$ & $\sqrt{E n_{1}{ }^{2}+E n_{2}{ }^{2}}$ & $\sqrt{E n_{1}{ }^{2}+E n_{2}{ }^{2}}$ \\
\hline$\times$ & $E x_{1} \times E x_{2}$ & $\left|E x_{1} E x_{2}\right| \sqrt{\left(\frac{E n_{1}}{E x_{1}}\right)^{2}+\left(\frac{E n_{2}}{E x_{2}}\right)^{2}}$ & $\left|E x_{1} E x_{2}\right| \sqrt{\left(\frac{H e_{1}}{E x_{1}}\right)^{2}+\left(\frac{H e_{2}}{E x_{2}}\right)^{2}}$ \\
\hline$\div$ & $E x_{1} \div E x_{2}$ & $\left|\frac{E x_{1}}{E x_{2}}\right| \sqrt{\left(\frac{E n_{1}}{E x_{1}}\right)^{2}+\left(\frac{E n_{2}}{E x_{2}}\right)^{2}}$ & $\left|\frac{E x_{1}}{E x_{2}}\right| \sqrt{\left(\frac{H e_{1}}{E x_{1}}\right)^{2}+\left(\frac{H e_{2}}{E x_{2}}\right)^{2}}$ \\
\hline
\end{tabular}
Table 2.

Table 2. The basic operation of the cloud

\subsection{Integrated operation}

In our daily work, we have different views on the same thing. Therefore, it produces more than two clouds of the same type, and the integrated operation is to integrate these same types of clouds with a certain algorithm to get a more generalized concept. The calculation formula is as follows:

$$
\begin{array}{r}
E x=\frac{E x_{1} E n_{1}+E x_{2} E n_{2}+\cdots+E x_{n} E n_{n}}{E n_{1}+E n_{2}+\cdots+E n_{n}} \\
E n=E n_{1}+E n_{2}+\cdots+E n_{n} \\
H e=\frac{H e_{1} E n_{1}+H e_{2} E n_{2}+\cdots+H e_{n} E n_{n}}{E n_{1}+E n_{2}+\cdots+E n_{n}}
\end{array}
$$

\section{Comprehensive evaluation of cloud model}

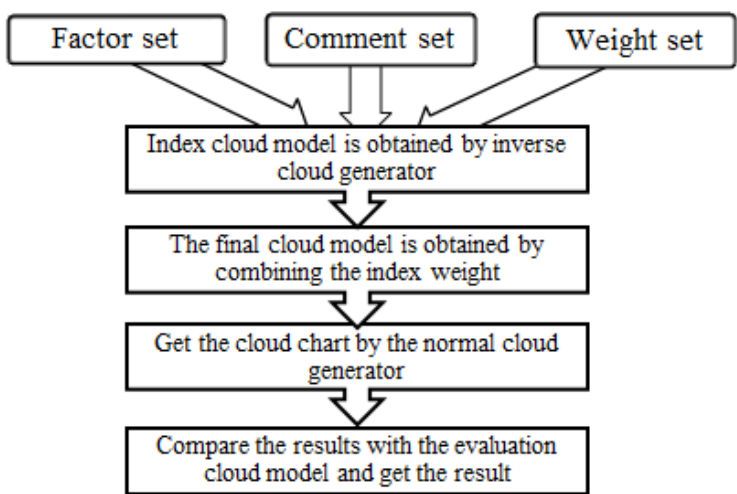

Figure 2. Cloud model comprehensive evaluation process.
This paper applies the cloud model to the comprehensive evaluation process as shown in Figure 2.

(1)According to the target object, some influential indicators are identified. The first level index to the two level index is $U=\left\{U_{1}, U_{2}, \cdots, U_{n}\right\}$. The two level index Ui can be divided into several three level index $U_{i}=\left\{U_{i 1}, U_{i 2}, \cdots, U_{i n}\right\}, i=1,2, \cdots, n$. The set of the above indexes is the factor set.

(2)After evaluating the above indicators, the set of commentary of all evaluation indicators is called the comment set, which is $V=\left\{V_{1}, V_{2}, \cdots, V\right\}$.

(3)The weight of each index of the above factor sets is calculated by cloud model. First, through many experts score the importance of the lower level indicators in the higher level, this paper divides the importance into five grades, and establishes a suitable cloud scale according to the grade of evaluation. The evaluation level and the matching cloud scale are shown in Table 3 and Table 4. Then the obtained fraction is processed by the reverse cloud generator to get the cloud model. If the weight cloud droplet distribution is scattered, it should be fed back and corrected until a more stable weight cloud is obtained. Finally, the weight is normalized to get the weight of the upper level of each index [12-13].

Table 3. Indicator importance level

\begin{tabular}{|c|c|}
\hline Weight class & Assignment interval \\
\hline Very important & {$[0.8,1]$} \\
\hline Important & {$[0.6,0.8)$} \\
\hline Less important & {$[0.4,0.6)$} \\
\hline General important & {$[0.2,0.4)$} \\
\hline Unimportant & {$[0,0.2)$} \\
\hline
\end{tabular}


Table 4. Indicator importance level cloud scale

\begin{tabular}{|c|c|}
\hline Weight class & Cloud model \\
\hline Very important & $(1,0.103,0.013)$ \\
\hline Important & $(0.691,0.064,0.008)$ \\
\hline Less important & $(0.500,0.039,0.005)$ \\
\hline General important & $(0.309,0.064,0.008)$ \\
\hline Unimportant & $(0,0.103,0.013)$ \\
\hline
\end{tabular}

(4)According to the actual situation of the navigation environment of LNG ships, the expert group has found the highest evaluation value and the minimum evaluation value for its evaluation index. The evaluation index is divided into five grades, which is shown in Table 5. Then the two groups of evaluation values are obtained, using the reverse cloud generator to generate the highest evaluation cloud model and the lowest evaluation cloud model, and then use the two group of cloud models to get a more generalized cloud model.

Table 5. Rating of risk indicators

\begin{tabular}{|c|c|}
\hline Evaluation grade & Assignment interval \\
\hline Lowest & {$[0.8,1]$} \\
\hline Lower & {$[0.6,0.8)$} \\
\hline Ordinary & {$[0.4,0.6)$} \\
\hline Higher & {$[0.2,0.4)$} \\
\hline Highest & {$[0,0.2)$} \\
\hline
\end{tabular}

(5)The weight of all levels of the LNG navigation environmental risk assessment is combined with the evaluation values at all levels. According to the formula $C_{i}=\sum_{j=1}^{m}\left(C_{i j} \times W_{i j}\right)$, the cloud model of all levels of indicators can be calculated. After the final cloud model $\mathrm{C}$ is obtained, the cloud map generated by the cloud is compared with the cloud map of the navigation environment evaluation results. The evaluation result is the evaluation level which is the closest to the final cloud map. The results of the assessment of the risk of navigable environment at all levels are shown in Table 6.

Table 6. Risk assessment results level cloud scale

\begin{tabular}{|c|c|}
\hline Evaluation grade & Cloud model \\
\hline Lowest & $(1,0.103,0.013)$ \\
\hline Lower & $(0.691,0.064,0.008)$ \\
\hline Ordinary & $(0.500,0.039,0.005)$ \\
\hline Higher & $(0.309,0.064,0.008)$ \\
\hline Highest & $(0,0.103,0.013)$ \\
\hline
\end{tabular}

\section{Example analysis based on jiangsu seashore}

In order to meet the demand of natural gas in Jiangsu Province, improve the capacity of natural gas supply, improve the supply pattern and ensure the safety of gas supply, the LNG project is to be set up in the coastal area of Jiangsu province. The construction of this project can effectively solve the problems of energy supply security and environmental protection. Therefore, the risk assessment can be carried out with the cloud model.

\subsection{Evaluation index of cloud weight}

Ten experts of the marine environmental safety assessment are invited to score the indicators at all levels of Jiangsu coastal LNG navigation environmental risk assessment. It takes the proportion of competency in human factors as an example, see Table 7. The score of competency is processed by inverse cloud generator. The results are fed back and corrected until the stable cloud map is obtained. Finally, the weight cloud $w_{11}=$ $(0.708,0.024,0.002)$ of the competence is obtained, and the method of obtaining the weight cloud of other indexes is also the same. The weight cloud is normalized to get the weight cloud at all levels, see Table 8 .

Table 7. Competency of human factors in the weight of the score

\begin{tabular}{|c|c|c|c|c|c|}
\hline Expert & $\mathbf{1}$ & $\mathbf{2}$ & $\mathbf{3}$ & $\mathbf{4}$ & $\mathbf{5}$ \\
\hline Weight scoring & 0.68 & 0.72 & 0.71 & 0.75 & 0.72 \\
\hline Expert & $\mathbf{6}$ & $\mathbf{7}$ & $\mathbf{8}$ & $\mathbf{9}$ & $\mathbf{1 0}$ \\
\hline Weight scoring & 0.70 & 0.71 & 0.72 & 0.69 & 0.72 \\
\hline
\end{tabular}

Table 8. The weights of the indicators at all levels

\begin{tabular}{|c|c|c|c|}
\hline $\begin{array}{c}\text { Secondary } \\
\text { index } \\
\text { weight }\end{array}$ & $\begin{array}{l}\text { Weight cloud } \\
\text { model }\end{array}$ & $\begin{array}{c}\text { Third-level } \\
\text { index } \\
\text { weight }\end{array}$ & $\begin{array}{l}\text { Weight cloud } \\
\text { model }\end{array}$ \\
\hline \multirow{3}{*}{$w_{1}$} & \multirow{3}{*}{$(0.268,0.024,0.003)$} & $w_{11}$ & $(0.429,0.024,0.002)$ \\
\hline & & $w_{12}$ & $(0.258,0.021,0.002)$ \\
\hline & & $w_{13}$ & $(0.314,0.022,0.003)$ \\
\hline \multirow{3}{*}{$w_{2}$} & \multirow{3}{*}{$(0.237,0.014,0.003)$} & $w_{21}$ & $(0.308,0.021,0.002)$ \\
\hline & & $w_{22}$ & $(0.368,0.020,0.002)$ \\
\hline & & $w_{23}$ & $(0.324,0.021,0.002)$ \\
\hline \multirow{5}{*}{$w_{3}$} & \multirow{5}{*}{$(0.279,0.019,0.002)$} & $w_{31}$ & $(0.151,0.019,0.002)$ \\
\hline & & $w_{32}$ & $(0.162,0.018,0.002)$ \\
\hline & & $w_{33}$ & $(0.230,0.021,0.003)$ \\
\hline & & $w_{34}$ & $(0.198,0.023,0.004)$ \\
\hline & & $w_{35}$ & $(0.259,0.022,0.002)$ \\
\hline \multirow{4}{*}{$w_{4}$} & \multirow{4}{*}{$(0.216,0.025,0.002)$} & $w_{41}$ & $(0.274,0.025,0.005)$ \\
\hline & & $w_{42}$ & $(0.264,0.022,0.002)$ \\
\hline & & $w_{43}$ & $(0.234,0.018,0.003)$ \\
\hline & & $w_{44}$ & $(0.227,0.019,0.003)$ \\
\hline
\end{tabular}

\subsection{Third-level index cloud model}

Taking the capacity of three level indicators as an example, the maximum and minimum scores are scored, see Table 9. The maximum cloud model and minimum cloud model are obtained by using the type $(1) \sim(3)$. The integrated cloud model is $C_{11}=(0.875,0.061,0.016)$, and other three levels of cloud model can be obtained by using the type (4) (6), see Table 10 .

Table 9. The score of the competency

\begin{tabular}{|c|c|c|c|c|c|}
\hline Expert & $\mathbf{1}$ & $\mathbf{2}$ & $\mathbf{3}$ & $\mathbf{4}$ & $\mathbf{5}$ \\
\hline Maximum & 0.90 & 0.95 & 0.90 & 0.95 & 0.85 \\
\hline Minimum & 0.85 & 0.85 & 0.85 & 0.90 & 0.80 \\
\hline Expert & $\mathbf{6}$ & $\mathbf{7}$ & $\mathbf{8}$ & $\mathbf{9}$ & $\mathbf{1 0}$ \\
\hline
\end{tabular}




\begin{tabular}{|c|c|c|c|c|c|}
\hline Maximum & 0.85 & 0.95 & 0.90 & 0.95 & 0.90 \\
\hline Minimum & 0.80 & 0.90 & 0.85 & 0.85 & 0.87 \\
\hline
\end{tabular}

\subsection{Other index cloud models}

According to the index value and its weight of the third-level index which has been calculated, we can calculate the cloud model of the upper level index. Taking the determination process of the two level index artificial factor cloud model as an example, the cloud models of the third-level index corresponding to human factors are $C_{11}=(0.875,0.061,0.016), \quad C_{12}=$ $(0.862,0.043,0.019) \quad, \quad C_{13}=(0.835,0.036,0.021)$ respectively. The calculation of cloud models for human factors is as follows:

$$
C_{1}=\left(\begin{array}{l}
w_{11} \\
w_{12} \\
w_{13}
\end{array}\right)^{T} \circ\left(\begin{array}{l}
C_{11} \\
C_{12} \\
C_{13}
\end{array}\right)
$$$$
=\left[\begin{array}{lll}
E x_{w_{11}} & E n_{w_{11}} & H e_{w_{11}} \\
E x_{w_{12}} & E n_{w_{12}} & H e_{w_{12}} \\
E x_{w_{13}} & E n_{w_{13}} & H e_{w_{13}}
\end{array}\right]^{T} \circ\left[\begin{array}{lll}
E x_{C_{11}} & E n_{C_{11}} & H e_{C_{11}} \\
E x_{C_{12}} & E n_{C_{12}} & H e_{C_{12}} \\
E x_{C_{13}} & E n_{C_{13}} & H e_{C_{13}}
\end{array}\right]
$$$$
=\left[\begin{array}{lll}
E x_{w_{11}} E x_{C_{11}} & +E x_{w_{12}} E x_{C_{12}} & +E x_{w_{13}} E x_{C_{13}} \\
E n_{w_{11}} E n_{C_{11}} & +E n_{w_{12}} E n_{C_{12}} & +E n_{w_{13}} E n_{C_{13}} \\
H e_{w_{11}} H e_{C_{11}} & +H e_{w_{12}} H e_{C_{12}} & +H e_{w_{13}} H e_{C_{13}}
\end{array}\right]^{T}
$$$$
=\left(E x_{C_{1}}, E n_{C_{1}}, H e_{C_{1}}\right)
$$

According to the basic operation of clouds, the cloud model of human factors can be calculated to be $C_{1}=(0.860,0.065,0.022)$. The calculation method of cloud models of other indicators at various levels is the same as above, as shown in Table 10.

Table 10. Risk assessment index cloud model

\begin{tabular}{|c|c|c|c|}
\hline \multicolumn{2}{|c|}{$\begin{array}{c}\text { Secondary index cloud } \\
\text { model }\end{array}$} & \multicolumn{2}{|c|}{$\begin{array}{c}\text { Third-level index cloud } \\
\text { model }\end{array}$} \\
\hline \multirow{3}{*}{$C_{1}$} & \multirow{3}{*}{$(0.860,0.065,0.022)$} & $C_{11}$ & $(0.875,0.061,0.016)$ \\
\hline & & $C_{12}$ & $(0.862,0.043,0.019)$ \\
\hline & & $C_{13}$ & $(0.835,0.036,0.021)$ \\
\hline \multirow{3}{*}{$C_{2}$} & \multirow{3}{*}{$(0.897,0.048,0.025)$} & $C_{21}$ & $(0.923,0.059,0.026)$ \\
\hline & & $C_{22}$ & $(0.905,0.049,0.026)$ \\
\hline & & $C_{23}$ & $(0.863,0.052,0.023)$ \\
\hline \multirow{5}{*}{$C_{3}$} & \multirow{5}{*}{$(0.756,0.045,0.022)$} & $C_{31}$ & $(0.854,0.033,0.015)$ \\
\hline & & $C_{32}$ & $(0.752,0.035,0.023)$ \\
\hline & & $C_{33}$ & $(0.736,0.039,0.016)$ \\
\hline & & $C_{34}$ & $(0.728,0.023,0.018)$ \\
\hline & & $C_{35}$ & $(0.741,0.025,0.022)$ \\
\hline \multirow{4}{*}{$C_{4}$} & \multirow{4}{*}{$(0.582,0.043,0.018)$} & $C_{41}$ & $(0.697,0.043,0.017)$ \\
\hline & & $C_{42}$ & $(0.675,0.025,0.016)$ \\
\hline & & $C_{43}$ & $(0.386,0.034,0.014)$ \\
\hline & & $C_{44}$ & $(0.539,0.031,0.015)$ \\
\hline
\end{tabular}

\subsection{Final cloud model establishment and index analysis at all levels}

According to the above conclusion, the cloud model of Jiangsu coastal LNG navigation environment risk assessment is $C=(0.780,0.080,0.023)$. The cloud map of the final result is compared with the cloud model at all levels in the Table 6 cloud scale. The result, as shown in Figure 3, is between "lowest" and "lower" and closer to the "lower" risk assessment of the navigation environment of the ship's navigable ships in the coastal area of Jiangsu. Therefore, it can be considered that its rating is "lower".

By analyzing Figure 4 and Figure 5, it shows that the evaluations of artificial factors and ship factors are between "lowest" and "lower" and is closer to "lowest". Therefore, the evaluation levels of human factors and ship factors are "low"; As shown by Figure 6, the environmental factor index is between "lowest" and "lower", and Closer to "lower", so it can be considered that the evaluation of environmental factors is "lower"; As shown in Figure 7, the management factor index is between "ordinary" and "lower", and closer to "ordinary", so it is considered that the evaluation level of management factors is "ordinary".

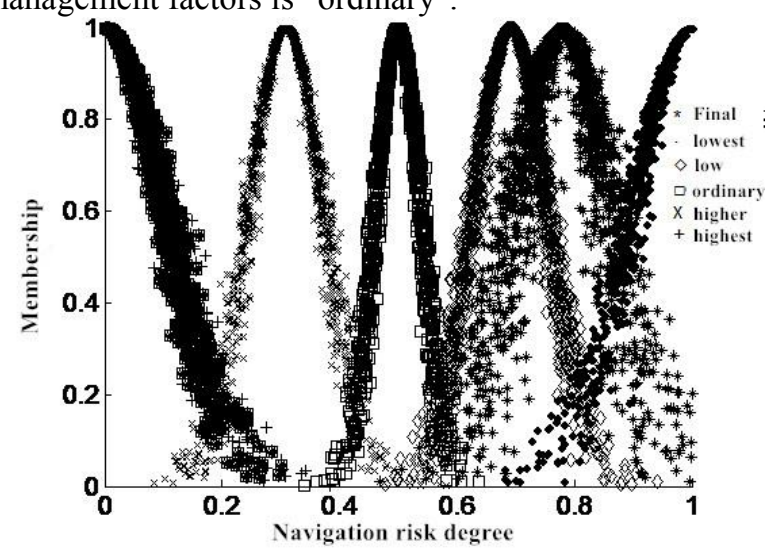

Figure 3. Target risk assessment cloud.

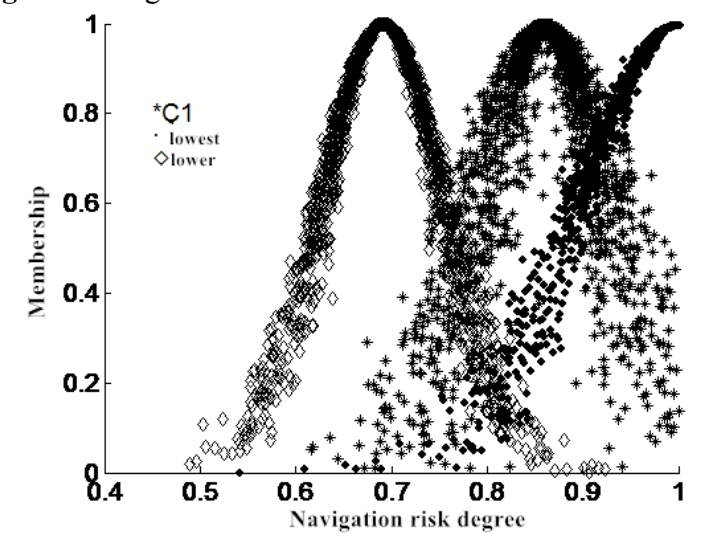

Figure 4. The cloud of human factors indicators.

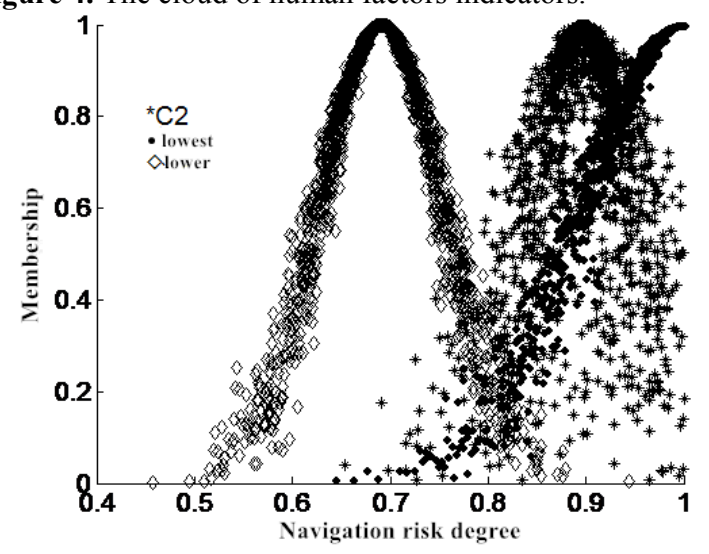

Figure 5. The cloud of the ship factors indicators.

LNG crew are trained professionally and LNG ships are built well. Therefore, the risk of accidents is lower in 
the two aspects of human factors and ship factors. With the continuous development of the port, the traffic in the main channel is becoming more and more busy and the traffic flow in the channel is increasing, so the safety of navigation is affected adversely. Therefore, environmental factors will have a certain impact on the navigation of Jiangsu seashore. Because of the new construction of the wharf, the lag of navigation supervision equipment and the particularity of $\mathrm{LNG}$, involving many aspects and large indeterminacy, the impact of management factors on navigation is relatively large. In the future, the local relevant department is likely to improve wharf on the two aspects of environmental factors and management factors.

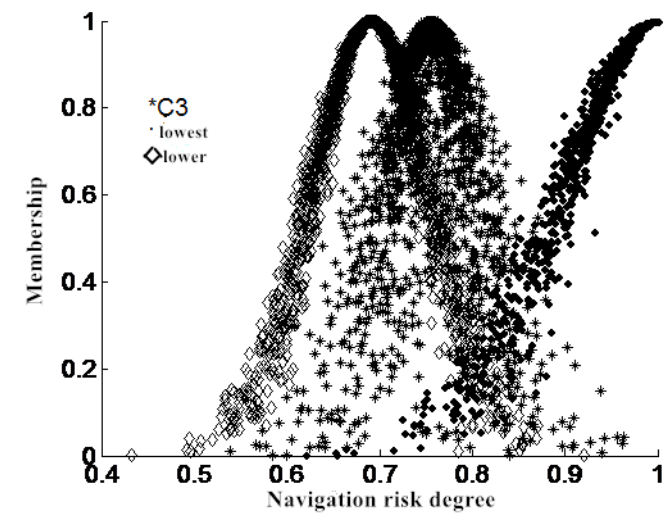

Figure 6. The cloud of the environment factors indicators.

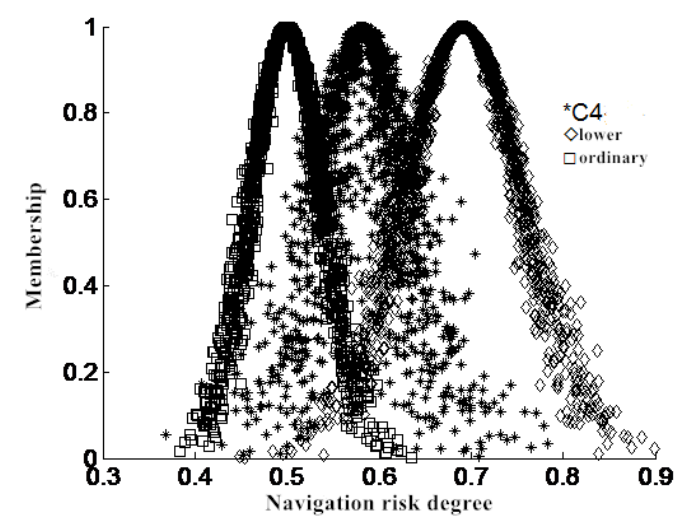

Figure 7. The cloud of the management factors indicators.

\section{Conclusion}

In this paper, we make full use of the advantages of the cloud model which can be used to transform the qualitative problem into the quantitative problem and take full consideration of the randomness and fuzziness of the sample, and combine the Delphi method to determine the cloud weight and cloud model of all levels of the LNG navigation environmental risk assessment system. Applying the above theories to analyze the navigation environment of the coastal LNG ships in Jiangsu. In this way, the MATLAB software is used to simulate the cloud map, which directly reflects the risk assessment level of the Jiangsu littoral indicators, and then we summarize and analyze the evaluation results. It provides a reasonable direction for the follow-up development of the navigation environment of Jiangsu coastal LNG ships, and can also be used as a reference for other regions for the navigation safety of LNG ship, which provides support of theory and practice for the development of shipping safety.

\section{Acknowledgment}

This work is supported by National Natural Science Foundation (NNSF) of China under Grant 51709032 and the Fundamental Research Funds for the Central Universities under Grant 3132018153 and Grant 3132018282 .

\section{References}

1. Ma jinjing, Huangpu lixia, Han li, et al. Current status and prospect of LNG in land water transportation safety standards at home and abroad[J]. Natural Gas Industry, 2015,(12):117-123.

2. Walter Chukwunonso Ikealumba,Hongwei Wu. Effect of atmospheric and sea stability on liquefied natural gas (LNG) dispersion: Implications to Australian LNG marine transport[J]. Fuel,2017,197.

3. Huang $\mathrm{P}, \mathrm{Du} \mathrm{Z}$, Cheng C. Navigation Safety Evaluation of Xiamen port Based on AHP-Fuzzy[A]. Proceedings of 2015 Joint International Mechanical, Electronic and Information Technology Conference [C]. 2015:10.

4. Zhu jingjun, Lan peizhen, $\mathrm{Xu}$ shenghao. Comprehensive port navigation safety evaluation[J]. Navigation of China, 2015,38(04):79-82. [2017-08-04].

5. Zheng yibin, Liu yu. Evaluation on maintenance level of provincial inland waterway based on factor analysis[J]. Port\& Waterway Engineering, 2013, (06):143-148.

6. Fan yaotian, Wang chi. Evaluation methods of Severity level of water traffic flow conflict based on BP neural network[J]. Journal of Transport Information and Safety,2017, (02):23-29.

7. Li lianbo, Liu junpo, Niu jiawei, et al. Weighted grey relative analysis and prediction for marine accidents in Liaoning waters[J]. Journal of Jiangsu University of Science and Technology (Natural Science Edition) ,2016,(06):605-609.

8. Zhang S B, Chun-Xiang X U, Yu-Jun A A. Study on the Risk Evaluation Approach Based on Cloud Model[J]. Journal of University of Electronic Science \& Technology of China, 2013, 42(1):92-97+104

9. Zhou Y, Wang L. Multi Level Fuzzy Comprehensive Evaluation Method Based on Cloud Model Theory[J]. Computer Simulation,2016,33(12):390-395.

10. Niu erxuan, Meng bin, Shen siwei. Evaluation model and empirical study of port enterprise green logistics based on cloud model[J]. Journal of Dalian Maritime University,2017, (02):67-74.

11. Zhang yong, Zhao dongning, Li deyi. The Similar Cloud and the Measurement Method[J]. Information and Control, 2004,02:129-132.

12. Liu cuilian, Yang liu, Liu jianmei. Application of cloud model to evaluation on port low-carbon green 
development $[\mathrm{J}]$. Journal of Shanghai Maritime University,2015,04:31-36.

13. $\mathrm{Xu}$ Zheng-jie, Zhang You-peng, Su Hong-sheng. Application of risk assessment on fuzzy comprehensive evaluation method based on the cloud model $[\mathrm{J}]$. Journal of Safety and Environment, 2014,14(2):69-72. 